\title{
A Rare Case of Breast Filariasis
}

\author{
Dr. Swati Chouhan M.B.B.S, M.D ${ }^{1 *}$, Dr. Sandeep Nautiyal M.B.B.S, M.D ${ }^{2}$
}

${ }^{1}$ Dept. of Pathology, Apex Hospital, Varanasi, Uttar Pradesh India

${ }^{2}$ Dept. of Pathology, Apex hospital, Varanasi, Uttar Pradesh

DOI: $10.36347 /$ sjmcr.2020.v08i11.016

| Received: 21.10.2020 | Accepted: 04.11.2020 | Published: 30.11 .2020

*Corresponding author: Dr. Swati Chouhan

Abstract

Introduction: Filariasis is a major health hazard around the globe causing 120-129 million cases in over 72 countries. Cases with breast as primary site for the parasite are uncommon and have been reported in females. Here we present a case of a male patient with filariasis of breast which is extremely rare. Case report: A 55-year-old male presented to the outpatient department with a mildly painful swelling in his left breast in sub areolar region. The smears from the aspirate showed cystic and phagocytic macrophages, few microfilaria forms and few fibro-fatty fragments in haemorrhagic background. Conclusion: Filariasis of the breast is an uncommon condition and can cause a diagnostic dilemma at times. Hence a high index of suspicion especially in patients from endemic areas is required.

Keywords: Filariasis, breast, fnac.

Copyright (C) 2020 The Author(s): This is an open-access article distributed under the terms of the Creative Commons Attribution 4.0 International License (CC BY-NC 4.0) which permits unrestricted use, distribution, and reproduction in any medium for non-commercial use provided the original author and source are credited.

\section{INTRODUCTION}

Filariasis is a major health hazard around the globe causing 120-129 million cases in over 72 countries and causing incapacitation and disfigurement in over 40 million $[1,2]$. Being an endemic in tropics it affects India, Africa and South American countries first two accounting for more than two thirds of the cases load [2].

Wuchereriabancrofti accounts for more than $90 \%$ of the cases of the world followed by Brugiamalayi and Brugiatimori [3]. Transmitted by the Culex mosquito, humans serve as the definitive host for the nematode. Lymph nodes and lymphatic vessels are most common sites which adult parasite infects. Cases with breast as primary site for the parasite are uncommon [4] and have been reported in females. Here we present a case of a male patient with filariasis of breast which is extremely rare.

\section{Case Report}

A 55-year-old male presented to the outpatient department with a mildly painful swelling in his left breast in sub areolar region. He had first noticed the swelling 3 weeks back and stated that the size was constant. On examination, a $2 \times 2 \mathrm{~cm}$ swelling was seen in the sub areolar region of the left breast being soft with vague margins and was mildly tender on palpation but no axillary lymph nodes were palpable.

FNAC was performed by a $22 \mathrm{G}$ needle fitted to a $10 \mathrm{cc}$ syringe and yielded a granular material admixed with blood. The smears were stained with haematoxylin and eosin $(\mathrm{H}$ and $\mathrm{E})$ stain. The smears from the aspirate showed cystic and phagocytic macrophages (figure-1), few microfilaria forms and few fibro-fatty fragments in haemorrhagic background. The microfilariae were rounded anteriorly and uniformly tapering posteriorly with a clear space free of nuclei at the caudal end - thus morphologically resembling $W$. bancrofti(figure-2). There was presence of few ductal cell clusters of breast as well (figure-3). MF spot test for microfilariae serology was performed and was found positive. A diagnosis of filariasis of breast with cystic lesion was made. The patient was treated with amoxicillin-clavulinic acid, albendazole, and diethylcarbamazine (DEC). The swelling had reduced when the patient came for follow-up after 2 weeks. 


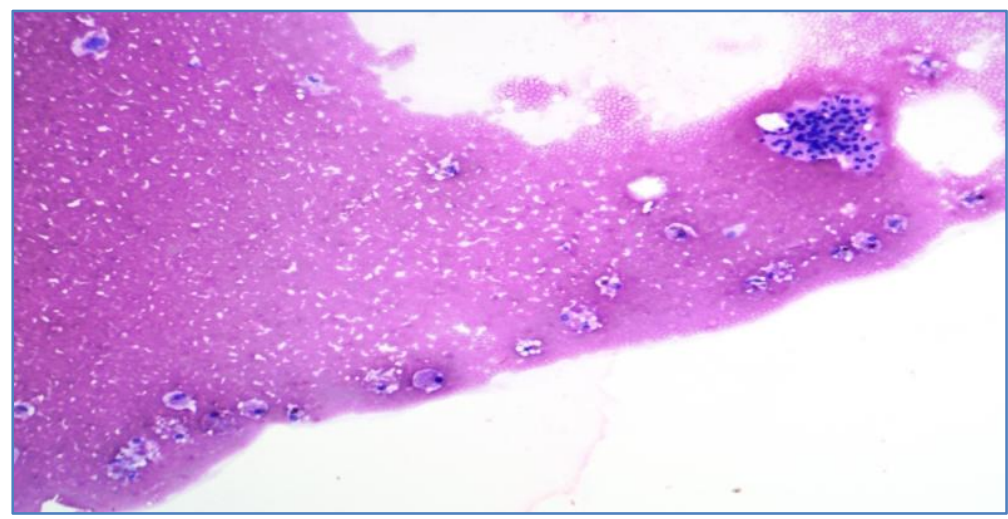

Fig-1: showing cystic and phagocytic macrophages

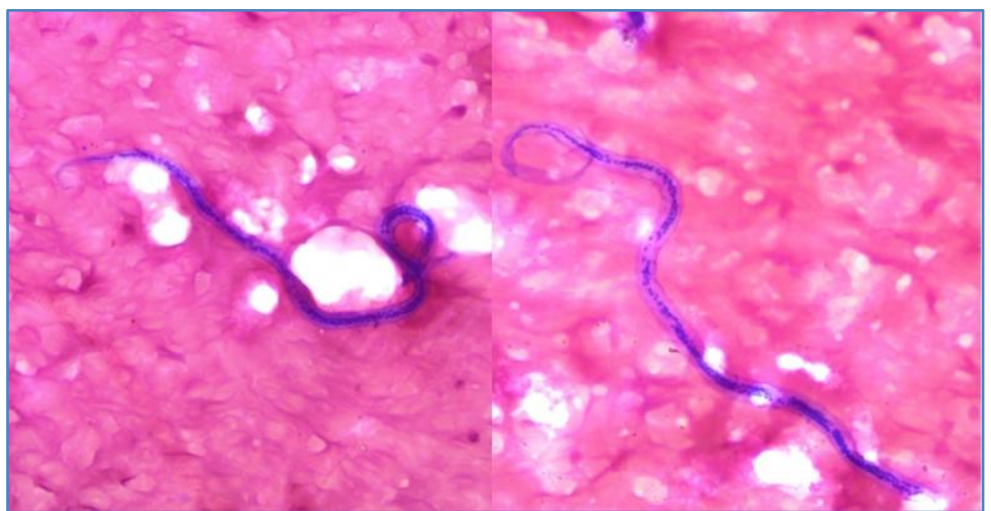

Fig-2: Showing microfilariae with morphology of W. bancrofti

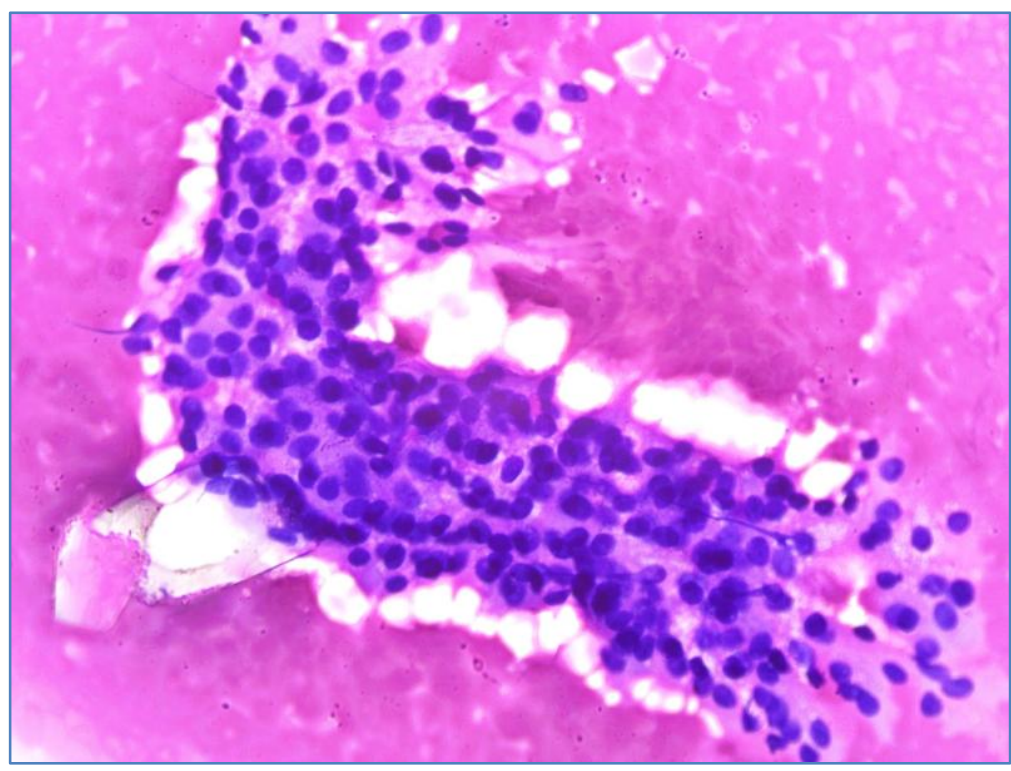

Fig-3: Showing benign ductal cells

\section{DISCUSSION}

Filariasis in India has a very ancient history since it has been reported from very early times by famous Hindu physicians like Susruta and Madhavakara [2]. India has the largest number of filarial cases across the globe and about 600 million people live in endemic areas [5]. It is quite rare to find microfilaria in routine cytological smears and body fluids despite of the great number of cases around the world.
There are eight species of microfilaria of which $W$. bancrofti, $B$. Malayi, and $B$. timori are responsible for lymphatic filariasis. Of these, the first two are common in India and they show nocturnal periodicity. Humans serve as the definitive host while infected mosquitos (Culexquinquefasciatus for bancroftianfilariasis and Mansonia mosquitos for brugianfilariasis) serve as the vectors. The adult worms harbour in the lymphatic system of man. The males are 
about $40 \mathrm{~mm}$ long and the females range between 50 and $100 \mathrm{~mm}$ in length. The viviparous females usually give rise to as many as 50,000 microfilariae per day [6].

Lymphatic filariasis presents with occasional febrile or inflammatory episodes. It is the initiation of the host's inflammatory immune reaction, which is responsible for the symptoms and signs associated with the filarial affliction of breast [7]. Intact worms produce minimal tissue reaction while degenerating parasites provoke inflammatory cell infiltration- mainly eosinophil's and occasionally development of epitheloid granulomas [1]. The involved lymphatic vessels are eventually blocked and replaced by fibrous tissue, and the patient may present with a palpable breast mass i.e. a filarial granuloma [8].

Most common site is upper outer quadrant of breast, but central or periareolar nodules occur with notable frequency [9-11]. Most of the lesions involve subcutaneous tissue and present as a hard mass with cutaneous attachment. Sometimes accompanying inflammatory changes in overlying skin including edema of the skin (peau d' orange) and enlargement of axillary lymph nodes make it clinically indistinguishable from carcinoma

\section{CONCLUSION}

Filariasis of the breast is an uncommon condition and can cause a diagnostic dilemma at times. Hence a high index of suspicion especially in patients from endemic areas is required. FNA cytology appears to be a more convenient and effective diagnostic tool in patients with mass lesions. Demonstration and identification of the parasite in smears helps in avoiding surgical excision and early institution of prompt therapy especially in young patients.

\section{REFERENCES}

1. Nutman TB. Insights into the pathogenesis of disease in human lymphatic filariasis. Lymphat Res Biol. 2013;11(3)

2. Upadhyaya V, Upadhyaya D N, Sarkar S. An interesting case of breast filariasis. Indian J Radiol Imaging. 2006;16:915-7

3. Chakrabarti I, Das V, Halder B, Giri A. Adult filarial worm in the aspirate from a breast lump mimicking fibroadenosis. Trop Parasitol. 2011;1:129-31

4. Gupta V, Vats AD, Gupta V. Use of FNAC in diagnosis of microfilaria of breast: A case report. J Integr Health Sci. 2016;4:37-9

5. Barwad, Adarsh. "Breast filariasis." IDCases vol. 14 e00453. 7 Sep. 2018.

6. Park K. Epidemiology of communicable disease. Textbook of Preventive and Social Medicine. $21^{\text {st }}$ ed. Jabalpur: BanarsidasBhanot Publishers; 2011. p. 244-50.

7. Sahai K, Kapila K, Verma K. Parasites in fine needle breast aspirates- assessment of host tissue response. Postgrad Med J. 2002; 78:165-7.

8. Friedman PD, Kalisher L. Case 43: filariasis. Radiology. 2002; 222(2):515-517.

9. Rosen PP. 2nd ed. Lippincott Williams and Wilkins; Philadelphia: 2001. Rosen's Breast Pathology; 65-75. Chapter 4, Specific infections.

10. Pant I, Singh PN. Filariasis of breast - a report of two cases, an unusual site to be involved. J Cytol. 2003; 20:206-207.

11. Singh Naorem G. ChatterjeeLeena. Filariasis of the breast, diagnosed by fine needle aspiration cytology. Ann Saudi Med. 2009;29(5):414-415. 